\title{
THE EFFECT OF LS APPROACH ON IRAQI EFL INTERMEDIATE SCHOOL PUPILS' ACHIEVEMENT
}

\author{
*Rafal Lateef Jasim, **Bushra Sadoon Al-Noori \\ *MA. Student, **Assistant Professor, \\ English department, University of Baghdad \\ College of Education for Human Sciences -Ibn Rushd-University of Baghdad \\ Baghdad, Iraq
}

DOI: $10.37648 / \mathrm{ijrssh.v10i03.020}$

Received: $08^{\text {th }}$ June, 2020; Accepted: $29^{\text {th }}$ June, 2020; Published: $18^{\text {th }}$ July,2020

\begin{abstract}
Pupils' achievement, in English language teaching-learning, considers the most important goal that should be achieved in the educational process, also it is the major matter that should be taken into consideration by educators, academics, and teachers. Unfortunately, Iraqi pupils' achievement in English language is weak, undeveloped and under the average in comparison to their achievement in other school subjects and that may be attributed to many different issues which need solutions. Therefore, the current study aims to improve the pupils' achievement by utilizing the LS Approach (Lesson Study Approach) in teaching English language and to investigate its effects on pupils' achievement.
\end{abstract}

To achieve the aim of this study, and its hypothesis, the randomized samples have been selected which consist of (61) pupils, from intermediate female school from, divided into two groups, the experimental group consists of (31) pupils which are taught by the LS Approach and the control group consists of (30) pupils to be taught conventionally.

The achievement post-test (written - oral) has been considered the instrument of the experiment in this study which it is given at the end of the experiment, and the result indicates that there is a statistical significance difference between the experimental and control group in the post-test, therefore, the effect size of the LS Approach is of high effect for the experimental group in the dimensional achievement test and this confirmed the beneficial and positive effect of the LS Approach in improving Iraqi pupils' achievement in English language teaching and learning process.

Keywords: Achievement in English, LS approach appearance, factors affecting achievement, principles enhancing achievement, components of LS approach, importance \& challenges of LS.

\section{INTRODUCTION}

Students' achievement has been the major matter of continuing debate among educators, academics, and policymakers. Having an ineffective teacher can significantly descend a student's achievement over time.The achievement, in all subjects, has been defined as the most important objective in the educational process, which refers to the major goal that should be performed by individuals in all cultures. The approaches of teaching in Iraq, according to many Iraqi researches, are old and all appear passive learning without deep understanding. This has guided to the acknowledgment of the significance of the cooperative teamwork teaching in education (Stigler and Hiebert, 1999: 136).

In the Iraqi educational field, there is a big problem with the time determined for the English lesson which is not appropriate 
for achieving a diversity of activities with heavy new English materials.

The teacher needs to walk around the room, to explain, to communicate with students, but because of a large number of students in each classroom teacher may lose the controlling, and also because each student does not learn in the same way and they need to learn according to their learning styles, all that refers to the need of more than one teacher in teaching the English language in order to increase the chance to reinforce and improve students' achievement. Therefore, Lesson Study Approach (LS) which based on teachers work together in a group (more than two teachers), and they engage in extended conversations while focusing on students learning and the development of specific outcomes (Richards \& Rodgers, 2014: 351), and that will solve these problems, facilitate learning, enhance teaching, and maybe raise students' achievement.

The purpose of the present paper is to investigate the effects of the LS approach on pupils' achievement in English.For that, this paper has showed the factors that effect on achievement, the principles that can enhancing pupils' achievement, and the importance of LS approach and its' effects on pupils' achievement.

\section{ACHIEVEMENT IN ENGLISH}

Edwards (2000:23) defines the need of achievement as "to do one's best, to be successful to accomplish tasks requiring skill and effort to be recognized authority, to accomplish something of great significance, to do a difficult job well, to solve difficult problems and puzzles and to be able to do things better than others, to write a great novel or play". Desai (1986: 177) defined academic achievement as "Learning outcomes which are the changes observed in the behavior pattern of pupils as a result of learning that takes place in schools through the teaching of school subjects". Achievement is defined as how well students have learned or what they are expected to know. On the other hand, "proficiency" is the ability to do something very well. An achievement test measures knowledge of specific information (what a person knows) while a proficiency test measures what an individual can do with what he or she knows.

Achievement tests in English are also frequently used by school districts and schools to help identify English-language learners, assign them to school programs, and reclassify them when English proficient (Brown; 2002:55).An achievement test is conducted at the end of an academic program to examine the extent to which the program has been successful in fulfilling the set goals. The program can be the end of a unit, a chapter, a course, etc. it brings to light the strengths and weaknesses of a program.Achievement tests are conducted either for the purpose of diagnosis or for testing the level of improvement in the student after completion of a course and identification of weak areas in which the student needs more guidance. The general pattern all over the world is to make students appear for achievement tests periodically and promoting them to higher levels only when they pass the tests. Hence, too much importance is given to achievement tests. However, these tests can be used for other fruitful purposes like deciding a future action plan for further study.

\section{FACtors Affecting ACHIEVEMENT}

Student achievement level cannot be stated in a vacuum, it depends upon a number of factors like personal and family background, their relationship with teachers, administrators, school heads, and larger systems like localities, local politics, and economics. The demographic factors are beyond one's control but the potential, personal abilities of students can be identified and studied. They help to create policies to improve learning. Hence, learning should be learner-centered and include areas like individual differences, cognition, metacognition, motivation, affective domain, developmental and social areas. The learner-centered model embraces the student's full life experiences. It moves from weaknesses to strengths of students.

According to Darling-Hammond \& Rothman (2011:79), the factors that affect each level of pupils' learning are several, like the macro-system (climate and culture), exo-system (community), mesosystem (interactions) and microsystem (personal factors). Each of these factors involves various other factors that effect on pupils' learning and their achievement that have explained below:

\section{A. Micro System Factors}

The micro-system factors include traits within the student and their interaction with other students and teachers. They are as follows:

1. Student Resiliency- The capacity to remain firm in spite of adverse circumstances. When there is an assurance of protection and a sense of security the impact of adversity is reduced.

- Strong and unconditional support from adults

- Getting mastery and recognition through opportunities

- Abilities, potentials and capacities of students, both cognitive and metacognitive

- Opportunities to think critically about the processes of learning as well as evaluation

- Learning that conforms to the real life of students, and their past, present, and future experiences.

- Selecting methods for learning to take place with autonomy 


\section{Health-related factors}

- Real-time learning that explains "Why do I have to do this?"

- Authentic inquiry and assessment

- Promotion of health and nutrition

3. Skill development and differences

- A different concept of achievement. Formative assessment to track the progress of learners and summative assessment to measure learning goals. One round of assessment before the beginning of instruction, assessment models and criteria shared in advance, providing feedback, offering choices for mastery

- All kinds and levels of assessment

- Cooperative learning

- Differential Instruction for students

- Peer tutoring that suits the community

- Modification of the school annual plan in order to cover time lost during vacations

4. Social and Moral Development takes place in family culture and community, and schools to some extent.

- Social Justice followed in Schools

- Inclusion moral development and value education in curriculum and clearly specified in vision and mission

- Creation of safety and security

\section{B. Meso-System Factors}

The interactions that surround each learner directly impact student achievement. The following factors play an important role in student success:

1. School climate as an open and safe learning environment

- Multicultural competence

- Building relationships that support the child in every way and in every matter leading to the promotion of moral values

- Protected team time, advisory time

\section{Partnering with parents}

- Special programs to interact with parents

- $\quad$ Love \& Logic parenting courses

- Mission, vision, values, and goals shared with parents and with their consensus.

\section{Teacher Development}

- Professional Learning Communities

- Personalized and teacher Driven
- Strengthened relationships for all stakeholders in the system

\section{Teachers as leaders}

- A clear notion of educational leadership, the role of leaders, well-managed system

\section{Teacher Evaluation}

- Mentoring

- Shared learning, shared responsibilities and supporting groups

- Continuous process

- Decisions through consensus of all

6. Peer Culture

- Equal representation of all groups.

- Healthy collaborative, democratic environment

- Clarity of vision, mission, and goals among students (methods to do so).

\section{Exo- and Macro-Systems Factors}

This layer consists of social and environmental factors that affect learning. Some interventions are possible in the mesosystem. There are interrelated risk factors given below which are common to items listed in the mesosystem and microsystem. Socioeconomic differences between families and communities, students from affluent families perform better than students who are economically backward. Advocacy and partnerships such as school and university alliances can meet needs within schools.

\section{Teaching Principles for Enhancing Pupils' ACHIEVEMENT}

The aim of teaching English is to enable the pupils to get command over language skills, which is to enable the pupils to read, write, and speak English fluently. But it is evident that the majority of the learners do not attain these goals. Pupils are able to achieve good grades in examinations but they do not remember anything that they learned in their language classes nor do they get practical command over the language. Like history and science, English is not a knowledge-based subject so it can't be learned merely by memorizing the words and rules of grammar. It is a matter of practice. Languages, including English, are skill-based.

As Thompson \& Wyatt stated, the power of expression in a language is a matter of skill rather than of knowledge. It is considered as a power that grows by exercise and not by knowing merely meanings or rules. Just as painting and dancing are practical skills, language is a skill-based subject that can be mastered only by continuous practice. To teach the English language effectively, the teacher should keep in mind the following principles of language teaching: 


\section{Principle of definite aims \& objective:}

The teaching of the English language becomes fruitful only when the teacher is conscious of definite aims and objectives. In the absence of aims and objectives, teaching may not remain a purposeful activity. The teacher should remember the four specific aims while teaching English to pupils. They are:

To understand spoken English.

To speak English.

To understand written English.

To write in English

Thompson \& Wyatt (1952) also remarked that "it is necessary that people should not only understand English when it is spoken or written but also, they should themselves be able to speak and write it".

\section{Principle of planning}

Effective teaching requires convenient planning. Principle of planning is a significant element of the teaching-learning system. Effective Planning involves five basic components: well-designed curriculum, learning objectives, teaching and learning activities, assessment mechanism, and evaluation methods to check the pupils' understanding of the topic.

Principle of planning provides a structure for essential learning in order that, a teacher cannot deviate from the main topic. It helps the teacher to grasp the aims and objectives of the course beforehand so that the teacher can be organized to complete the syllabus within the given timeframe. It can also help the teacher in the timely preparation of the lesson and confidence in delivery.

\section{Principle of motivation}

The most important factor in second or foreign language acquisition is motivation. The success of a student depends on the rate of teacher's motivation for pupils. Language teachers cannot teach the language effectively if they do not comprehend the relationship between motivation and its impact on language acquisition. So, the teacher's job is to innovate a friendly environment in which all the pupils feel recognized and valued. Motivate the pupils by providing previous year pupils' achievements. Language can be quickly learned if curiosity is created in it. Encourage the pupils to set short term goals and help them to achieve particular goals. By knowing pupils by name, the teacher can personalize the classroom environment. Motivation, both intrinsic and extrinsic is of supreme importance in the success of pupils at all stages. Teachers' supporting environment, unbiased feedback, friendly atmosphere have a great impact on language acquisition of pupils.

\section{Principle of creativity}

Creativity makes a difference in the classroom. In the process of teaching-learning, the teacher should encourage creativity in the classroom. Creative classrooms provide an environment where pupils are encouraged to express their ideas and think out of the box. In the world of the internet, teachers can incorporate creative learning by creating captivating lessons on various topics that boost pupils' ability to come up with imaginative ideas.

\section{Principle of feedback}

Feedback is an essential element of improving the learning process of the pupils. Feedback is acknowledged as a vital approach to facilitate pupils' development as independent learners in order to monitor, evaluate, and regulate their own learning. It has been proven that feedback enhances learning and improves pupils' outcomes. Giving feedback is an important skill for teachers in higher education and has a major influence on the quality of the pupils' learning process. Feedback can be delivered in the oral or written form and it can be given to an individual student or to the whole class. Through proper feedback, pupils are able to get guidance and opportunities for improvement by acknowledging their drawbacks.

\section{Principle of variety}

Variety is likewise one of the furthermost influential factors to enhance the teaching-learning process. Conventional methods of teaching are outdated now. The teacher can bring variety in the classroom by using different learning activities, feedback techniques, resources, and various teaching approaches to make the classroom lively and interesting.

\section{Principle of sympathy and cooperation}

Teaching-learning is a cooperative process. Teachers should provide encouragement and promote courteous behavior in the classroom. In the case of classroom disagreements, teachers should cultivate unbiased outlook and make a decision based on the best interests of all.

\section{Principle of self-learning}

Throughout the intensive lectures, spoon-feeding has been the traditional method of teaching in the classroom. Spoonfeeding is a sort of primarily teaching which consists of a teacher-centered style of instructions where the instructor provides the pupils with all of the information, they need to know for the course resulting in curbing independent thought and action (Collins American English Dictionary online, n.d.). In spoon-feeding sort of teaching-learning, the instructor conveys exactly what he/she wishes to teach. All that the pupils have to do is to take copious notes, memorize the material and they will be able to pass the test with a reasonable grade. Pupils 
become passive learners and they do not take any responsibility for their own learning in a spoon-feeding type of teaching and eventually forget what they learned when the course is completed. In a student-centered learning environment, the teacher can lay the foundation for independent thinking and problem-solving skills.

\section{Principle of group dynamics}

The teacher should promote pupils to contribute in activities and assignments of the group that encourages competitive spirit, mutual understanding, and fellow feeling. The dynamics principle of group stimulates enthusiasm in group activities that leads pupils to get more language practice as most of the activities are done in pairs or in groups. These group activities also develop confidence and independent thinking skills among pupils.

\section{Principle of drill \& Practice}

Palmer affirms that language learning basically considers a habit-forming process, a process during which we acquire new habits. Pupils need sufficient practice and drilling when they are learning a foreign language to do away with the mother tongue since the sound system of the new language is different from that of the mother tongue. Therefore, it is important for teachers to help the pupils to master the structures and sounds of the English Language.

\section{Principle of Repetition}

Repetition deems also one of the fundamental language teaching-learning techniques. Habits are formed through repetition. Pupils, in the process of learning, tend to forget things with the passage of time. It has been confirmed that things often repeated are best remembered. Therefore, the duty of the teacher is to apply the concept of repetition in the process of teaching-learning.

\section{Principle of activity (Learning by doing)}

In the traditional classroom, pupils are only passive recipients of the information. The concept of teaching-learning now a day has been altered from teacher-centric to the studentcentric. Activity-based teaching-learning alludes that pupils learn by doing various activities. The role of a teacher is not simply restricted to be as a teacher; but they need to play different roles like classroom manager, a facilitator, a mentor, communicator, and monitor in order to make the pupils actively involved in various types of activities that foster all-round development. Activity-based learning urges pupils to become dependent thinkers. The activities are not only building pupils' self-confidence but also develop healthy relationships amongst pupils themselves, and pupils and teachers.

\section{Principle of context and situation}

The main aim of teaching the English language is to empower the learner to use it. Subsequently, the purpose of the language is to enable them to use language, and it must be exercised in appropriate realistic situations or imaginary situations. Language learning is not crucial unless it is connected to practical life. Literal translation, mechanical drilling of words and structures is not only tedious but also makes the language learning ineffective. In situational language teaching, all the exchanges and sentences grow out of real situations so pupils can operate that knowledge in day-to-day life situations.

\section{Principle of rest \&Recreation}

Nowadays Technology has become an essential part of the current generation. The youth have become addicted to a new method of online communication through social media, twitter or they are expected to be seen as watching T.V programmers or playing videogames. There is no opportunity for rest and recreation that rejuvenate both mind and body. Teachers should take responsibility for arranging recreational activities for pupils. Recreation activities such as hiking, tree plantation, painting, drawing, organizing school events, drama, plays, and sports are not only refreshing the mind but also developing the rapport between the teachers and pupils, as also reduce stress and help pupils to feel more energized to perform better.

According to Brown (2001:212), these teaching principles and the role of a teacher in process of active teaching-learning of pupils have proved to be important tools in order to enhance pupils' participation in language learning activities in order to enhance their achievement.

\section{LS APPROACH APPEARANCE}

Lesson Study Approach (LS Approach) is a Japanese method of development of teachers. It is different from other methods because it does not consist of any kind of professional training. It is distinct since it is based on a cooperative study of live classroom lessons. It is looked upon as a basic and necessary educational approach that leads to the professional development of teachers (Stigler \& Hiebert, 1999). 'Jugyou', in Japanese refers to classroom instruction, and the Japanese word kenkyuu, means study or research. The LS Approach has originated from these two Japanese words. As per the translation of the two terms, the LS approach is described as a process that "consists of the study or examination of teaching practice" (Takahashi\& Yoshida, 2004: 437). LS approach goes is not a mere study of lessons; it is a systematic investigation and study of lesson teaching practices.According to Lewis (2002:48), the LS Approach is a teacher-led approach and its specialty lies in the fact that it is collaborative in nature. This approach is meant for the professional development of teachers 
and their improved performance in the classroom by the Japanese education community.

The LS approach has been practiced in education since the Meiji period (1868-1912) when its focus was to encourage teachers to look at their own performance, reflect upon it and develop themselves. The basic principle in this approach is that a real classroom situation is the best place to improve teaching practice (Stigler \& Hiebert, 1999:109). LS approach is a systematic approach. It consists of specific steps like planning, teaching, observing, revising, and re-teaching lessons. It helps teachers who teach at all grades and levels. Teachers work in teams and collaborate with each other at every step. They direct their combined efforts towards specific goals to bring about improvement in instruction. Stigler \& Hiebert, (1999) believe that the classroom is the best setting for teachers to enhance their professional skills. They define the LS approach as a process by which "practitioners engage as researchers and scholars in their own classrooms by developing and testing lessons and studying their impact on pupils. This practice provides a high-fidelity context in which teachers can build their content knowledge and pedagogical skills". LS approach involves a group of teachers who work together in order to achieve a common goal.

They involve observation, analysis, and revision of lesson plans (see figure 1). Hence, two main aspects of the LS Approach that evolve from the above discussion are working together in collaboration and making the actual classroom the premise for the development of teaching skills.

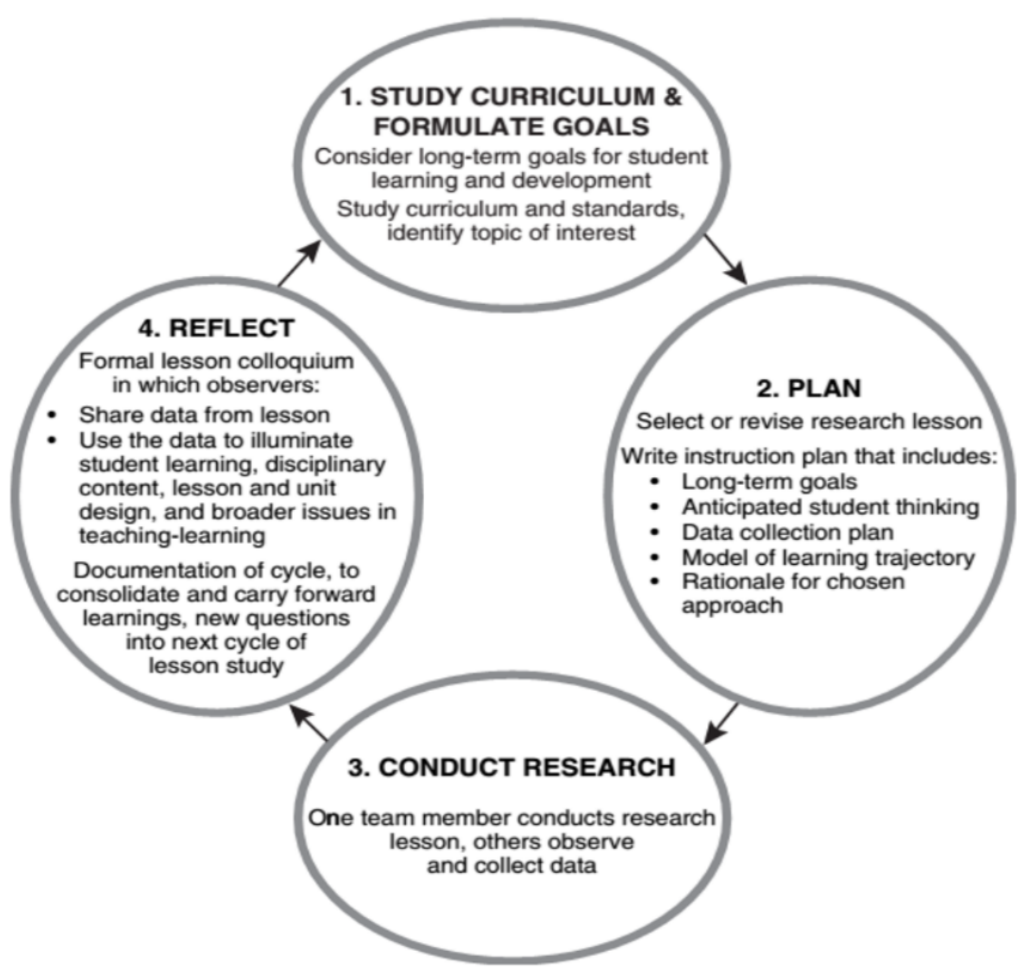

Figure 1. The LS approach cycle (Lewis et al. 2011: 2).

Another aspect, Isoda et al. (2007:20) detect a few more fundamental ideas about the practice of LS approach such as: -

1. Observing the lessons of other teachers is very helpful especially to pre-service teachers. Each teacher has different experiences of teaching while he/she was a student in school. Some of us are fortunate to get good teachers. Teachers under training generally try to emulate their own teachers who may not necessarily be perfect. Moreover, teaching different subjects requires different skills. Even teaching methods adopted for various topics can make a lot of difference. Hence, the more lessons one observes, the more their perspective widens. While observing, teachers can note the positive as well as a negative element in the teaching of others. This can help them to decide what to follow and what to avoid. In a classroom, observers can also see the responses of learners and the impact of teaching, which can help them in improving their own teaching practices.

2. It is good and desirable that highly experienced teachers who have developed excellent teaching skills and mastered the art of teaching should share their expertise with their colleagues.

3. In the LS approach, the primary focus is on the teacher yet, the ultimate attention is on developing the interest of 
pupils, motivating them, and maintaining the value of teaching (Elipane, 2012: 50).

In the LS approach process, teachers work together towards a common goal related to pupils' learning, they plan the lesson accordingly and then examine and discuss the pros and cons of the lesson and its performance ( Murata, 2011:4). Watanabe (2002:50) has observed that the LS approach experience enables teachers to examine various aspects of teaching such as; strategies, learning styles, plans, instructional materials, content, etc.

\section{The ESSENTIAL COMPONENTS IN THE LS APPROACH}

\section{Goal-setting}

LS approach is teacher-led, which makes it distinct from other approaches. (Takahashi\& Yoshida, 2004:436). The teachers set the goals so they themselves choose a topic that conforms to the goals. The topic chosen becomes the research lesson. Setting goals is the first step in the LS approach. The teachers get engaged in working out the details of the lesson as it would be conducted in the classroom situation. They plan a path leading to the set goals. They explore various possibilities and create local theories.

Murata (2011:6) observes that throughout the process, the nature of the goals changes gradually from general to specific. The research question is modified accordingly. The LS approach participants become the researchers in the performance of considering important factors towards attainment of the goals. The topic is decided at this point and the research goals are set. The goals are common and agreed upon by common consensus. Hence, the plan proceeds by creating a community of practice. The community is a result of collaboration and teamwork.

\section{The Lesson Plan}

Unfortunately, most teachers do not consider the lesson plan as important or essential. However, it is vital to the success of any lesson. Every detail of execution in the classroom, every instructional material is defined during lesson planning. The entire lesson is finalized. The lesson plan which is made in advance allows the teachers to keep ready all the teaching aids and materials to be used in the classroom. The necessary resources are tapped and materials are procured in advance.

The following factors must be taken into consideration regarding the LS approach plan:

1.All kinds of teaching-learning material including books, worksheets, pictures, models, and maps.

2. a range of teaching methods

3.The learning style of students, development of concepts in students, kinds of errors, problems and possible solutions, etc.
4. the academic level of students and assessment of their achievement status.

5.research related to the topic (Takahashi \&Yoshida, 2004: 440).

\section{Delivery of the LS approach}

Takahashi\& Yoshida (2004:441) have rightly said that in the LS approach, the research lesson is the most crucial part. Participants can learn through actual lesson observation, discussions, and reflection. It is necessary to identify a host school that will permit implementation of the Research Lesson and also permit outsiders and in-house staff to observe the lessons. This kind of arrangement can promote real professional development. In a conventional set-up, teachers or outsiders hardly get a chance to enter live classrooms and observe lessons carefully. Watching and observing helps to get an idea about various classroom practices, pedagogical aspects, and positive and negative aspects of teaching practice or content matter. It helps teachers to estimate where they stand in the picture, to avoid what does not work and it also boosts their morale and confidence. Extended resources from beyond the local school contexts can also be availed. The classroom experiences are shared hence, teachers can share professional knowledge. Live Research Lessons are a natural context for creating practicing communities of teachers who learn and develop together, share ideas, and collaborate throughout. They get a strong platform for discussion that proves to be fruitful.

\section{Discussion post-lesson or debrief session}

The post-lesson serves as a valuable platform for reactions, opinions, and presentation of ideas. It also gives an opportunity to assess whether the set goals have been successfully achieved. In the words of Watanabe (2002:37) a research lesson "must always include a post-lesson discussion in which all participants can reflect critically on the lesson". These discussions expand upon the understanding of various aspects of a lesson and provide an opportunity to assess how each participant makes sense from a range of observations of a Research Lesson. Participants can point out any flaw or shortcoming if noticed. Teachers can examine their own practices and perspectives and share them with all other participants. Thus. LS approach can enhance the professional knowledge of teachers. Participants can refer to research studies in the field and connect them to the Research Lesson. This will help the teachers to become more conscious and broaden their pedagogical understanding for better performance. Hence, the LS Approach is a rich experience for in-service as well as pre-service teachers. It affects cumulative learning and gives a chance to teachers for $100 \%$ participation. They play an important role which motivates them to be more creative and resourceful. They get a sense of satisfaction for 
being contributory in the process of education and pedagogy building. Each participant has something valuable to offer and in the LS approach, justice is done to each new idea. The knowledge base of the profession is enriched during the program. The collaborative efforts can be dispensed to the public. The entire teacher community can benefit. Eventually, it brings about uniformity in teaching practices in the region where it is implemented.

\section{THE IMPORTANCE AND CHALLENGES OF LS APPROACH}

Sarkar Arani and Fukaya (2009:24) confirm on the basis of their case studies and research that through LS approach, it is possible for teachers to analyze the lessons in detail. As a result, students can express themselves creatively and they remain active in the classroom, thus giving $100 \%$ participation in cooperative learning. They list the following rewards of the LS approach with regard to the quality of teachers and teaching: -

\section{Paying more attention to student variation}

Teachers can do complete justice to every individual pupil in the LS approach. They can observe each pupil carefully and monitor the progress. They can note down which pupils raise their hands and answer questions in the classroom. They can create an individual database and track the progress of each pupil. Pupils who have special problems or interests can also be spotted and separate opportunities can be provided to them for participating in group work. Sufficient attention can be paid to pupils who are active or docile, introverts, or extraverts.

\section{Looking for more effective ways of establishing and concluding lesson}

The activities in the teaching-learning process is meaningful to the actual life of students. Teachers can introduce a lesson by asking questions that are relevant to their daily lives. This motivates them to look forward to the lesson. At the end of the lesson, students and teachers discuss the lesson and related problems. They can rectify mistakes. All this can be recorded in a notebook and used either as a record or for the purpose of reference. It allows reflection and modification. Hence, the teaching-learning process is rendered as a purposeful activity.

\section{Designing learning for more mutual interaction}

Teachers who participate in the LS approach learn to design useful interactive activities that promote learning. Small groups can be made and activities assigned to each group. This enables teachers to note individual capacities as well as the qualities necessary for working in groups. The important thing is that teachers and students should work together.

\section{Looking for creative ideas}

LS approach is meant for training school teachers to adopt problem-solving techniques that lead to solutions. The process of problem-solving is more important than solutions. Pupils are required to apply their critical thinking skills in the act. Pupils learn to connect between thinking and action to facilitate an open learning environment. Thus, in a way, pupils are teachers as well as judges. They can decide the strengths of teachinglearning practices.

\section{Learning to assess and assessing to learn}

During the LS approach teachers get a chance to change their perceptions about the capacities of pupils and look in a different way even if they make mistakes. Mistakes can be utilized as a starting point for discussions that lead to positive effects. Instead of merely providing factual answers to questions, students go to the root of the issues and respond after deep reflection and interpretation. They construct knowledge effectively through total involvement. If teachers do not initiate challenging questions, students will lose interest and will stop asking or answering questions.

The questions must be related to the needs and interests of the students. Pupils must be given the necessary freedom and environment to pose questions and raise issues. A mistake must be considered as a result of a lack of thinking rather than a lack of academic ability. In this way, pupils will not feel intimidated while asking questions and will start thinking upon their own capacities and performance.

\section{Learning and reflection}

Teachers reflect on teaching aids, materials, designs, structure, decisions, and action on an individual level as well as part of a group. They analyze the lesson notes. They learn together with their colleagues and gather various perspectives regarding classroom activities. LS approach is not confined to theory and abstract principles. It goes beyond and expands to include skills and practical knowledge. Educational experiences based on self-reflection provide opportunities for selfevaluation and feedback.

\section{Learning through collaboration}

The LS approach proved to be extremely beneficial for teachers in many ways. They mastered the skills of teamwork effectively. When there are many participants, there are likely to be differences of opinion; however, if they are taken positively, they lead to more growth and opportunities. There is a possibility that members try to influence each other. Often, it was observed that previously neglected and discarded ideas were taken positively later. 
The educational system, school culture, and socio-economic background are some of the main challenges to the sustenance of LS approach (Sarkar Arani, 2006:42). Below is a list of some other factors related to sustenance.

1. The limited-time was available to teachers, their socio-economic background, and the status of their quality of teaching.

2. Absence of institutional support in collaborative attempts.

3. Lack of support for collaboration, group activities, and sharing of ideas or decisions regarding school management.

4. Greater dependence on individual performance rather than group potential.

5. Undue weightage is given to theory rather than practice and professional knowledge

6. Considering the LS approach as a method of rating teachers' performance rather than their professional enhancement.

7. Focus on the end outcome and neglect of the process and teaching instead of learning.

8. Anxiousness associated with observation of lessons by unknown, outside visitors.

9. Seeking immediate change and results without allowing sufficient time for the LS approach and its implementation.

\section{GUIDELINES FOR APPLYING THE LS APPROACH}

Sarkar and Fukaya (2009: 29) have suggested the following schemes that proved to be beneficial for various elements in the teaching community, and which led to an improvement in teaching.

1. Bring participants together and conduct informal and formal meetings for encouraging professional discussions.

2. From the beginning, make use of a language commonly understood in order to ensure good communication.

3. Share ideas through discussion with colleagues.
4. Make it a practice to share knowledge and practical experiences.

5. Identify the ideas that can be translated into actual practice.

6. Both, the process and the product are equally important to learn to value both.

7. Try to find a common goal that suits all stakeholders in education.

8. The role and responsibility of each participant must be made clear.

9. Create a culture based on improvement through collaboration and constant change.

10. Understand that change cannot be quick and it requires support from within and outside the school.

11. Realize that the LS approach is apparently simple but difficult to implement and practice.

12. Perceive the LS approach as a process rather than a project or an event.

It is necessary to pay careful attention to the cyclic process of the LS approach which plays a substantive role in teacher development. The sequence of the cycle is important. The most important phases are planning and observation.

\section{METHODOLOGY}

\section{PoPUlation AND SAMPLING}

In this study, the population includes pupils at AL-Thariat Intermediate School female pupils in the city of Baghdad during the academic year 2019 - 2020.Two sections have been selected to be the sample of the study. Section B which includes 31 pupils is chosen randomly to be the experimental group and section $\mathrm{C}$ which includes 30 pupils is selected randomly to be the control group. So, the total number of the sample is (61). The researcher has equalized the experimental and the control groups according to pupils' achievement scores in English language material at their first grade of intermediate school (Pre-Test), pupils' motivation, pupils' intelligence, and pupils' age.See table I. 
TableI: The equalization of the experimental and control groups inPre-test, Intelligence, Academic Motivation, and Pupils' age

\begin{tabular}{|c|c|c|c|c|c|c|c|c|}
\hline \multirow[b]{2}{*}{ Variable } & \multirow[b]{2}{*}{ Groups } & \multirow[b]{2}{*}{ No. } & \multirow[b]{2}{*}{$M$} & \multirow[b]{2}{*}{$S D$} & \multicolumn{2}{|l|}{ t-value } & \multirow[b]{2}{*}{ d.f } & \multirow[b]{2}{*}{ Sig. } \\
\hline & & & & & computed & critical & & \\
\hline \multirow[b]{2}{*}{ Pre-test Scores } & Experimental & 31 & 69,93 & 13,41 & \multirow[b]{2}{*}{0,056} & \multirow{8}{*}{2,00} & \multirow{8}{*}{59} & \multirow[b]{2}{*}{ No } \\
\hline & Control & 30 & 69,74 & 14,94 & & & & \\
\hline \multirow[b]{2}{*}{ Motivation } & Experimental & 31 & 90,45 & 5,99 & \multirow[b]{2}{*}{0,418} & & & \multirow[b]{2}{*}{ No } \\
\hline & Control & 30 & 89,80 & 6,17 & & & & \\
\hline \multirow[b]{2}{*}{ Intelligence } & Experimental & 31 & 35,00 & 7,46 & \multirow[b]{2}{*}{0,425} & & & \multirow[b]{2}{*}{ No } \\
\hline & Control & 30 & 34,10 & 9,00 & & & & \\
\hline \multirow[b]{2}{*}{ Age } & Experimental & 31 & 166,19 & 4,39 & \multirow[b]{2}{*}{0,132} & & & \multirow[b]{2}{*}{ No } \\
\hline & Control & 30 & 166,33 & 3,82 & & & & \\
\hline
\end{tabular}

\section{DATA ANALYSIS AND RESUltS}

In order to realize the aim of the current study which refers to know the effect of LS Approach on Iraqi EFL intermediate pupils' achievement and to verify its hypothesis, the results of the post-test are analyzed in order to find out if there are statistically significant differences between the mean score of the experimental group which is taught by the LS Approach and that of the control group which taught conventionally.To achieve that, the researcher has used the t-test for two independent samples in order to compare the experimental and the control groups in their achievement. See Table II.

Table II: The Mean Scores, Standard Deviation and T-Test Value of Two Independents sample for Both Groups in the Post-test

\begin{tabular}{|c|c|c|c|c|c|c|c|c|}
\hline \multirow[b]{2}{*}{$\begin{array}{l}\text { Variabl } \\
e\end{array}$} & \multirow[b]{2}{*}{$\begin{array}{l}\text { Grou } \\
p\end{array}$} & \multirow[b]{2}{*}{ No. } & \multirow[b]{2}{*}{$\begin{array}{l}\text { Mean } \\
\text { Score }\end{array}$} & \multirow[b]{2}{*}{$S D$} & \multicolumn{2}{|l|}{ t-values } & \multirow[b]{2}{*}{$\begin{array}{l}d . \\
f\end{array}$} & \multirow[b]{2}{*}{$\begin{array}{l}\text { Level of } \\
\text { significanc } \\
e\end{array}$} \\
\hline & & & & & $\begin{array}{l}\text { Compute } \\
d \\
\text { Values }\end{array}$ & $\begin{array}{l}\text { Critical } \\
\text { values }\end{array}$ & & \\
\hline : & Exp. & 31 & 76,323 & 11,137 & \multirow{2}{*}{4,566} & \multirow{2}{*}{2,000} & \multirow{2}{*}{59} & \multirow{2}{*}{0.05} \\
\hline 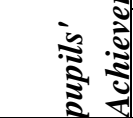 & Con. & 30 & 62,667 & 12,214 & & & & \\
\hline
\end{tabular}

As shown in Table 4.1 that the mean score of the experimental group is $(76,323)$ and that of the control group is $(62,667)$ in the achievement or post-test. The computed t-value $(4,566)$ is found to be higher than the critical t-value $(2,000)$ at 0.05 level of significance and (59) degree of freedom.

This result refers that there is a statistically significant difference between the two groups in the post-test. This difference is in favor of the experimental group pupils which are taught the English language by the LS Approach therefore, the first null hypothesis is rejected. All that will be more illustrated in figure 2 below: 


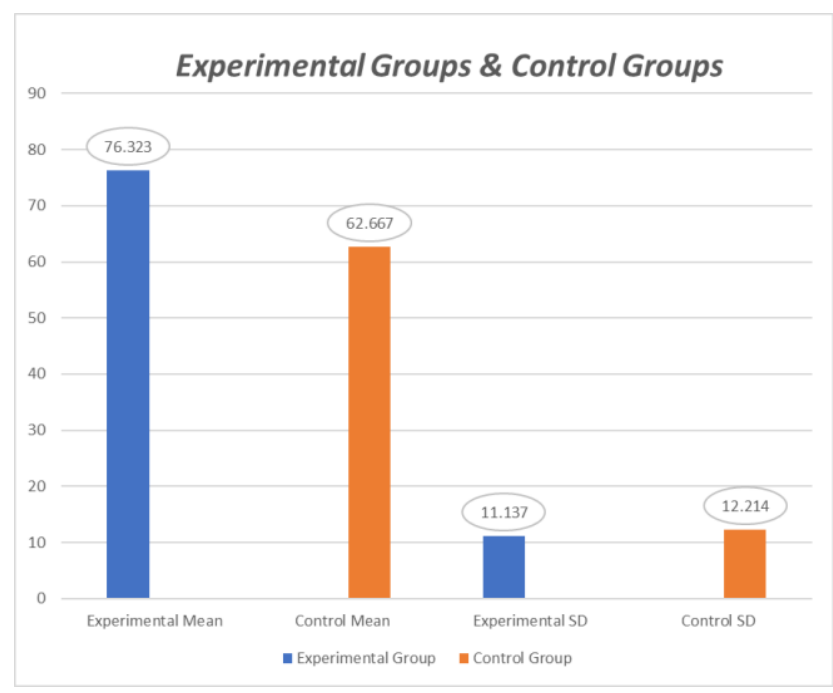

Figure 2. The Mean Scores of the Experimental and Control Groups in the Post-Test

The effect size can be extracted in this way by dividing the computed t-value by (the computed t-value + freedom degree), and knowing the size of the effect helps us determine the relative impact of the approach, and the ETA-Square value compared to the following criteria:

Simple effect: 0.01 .

Medium effect: 0.06 .

High effect: 0.14

The mean score, standard deviation and calculated t-value between the experimental and control groups have extracted in the post achievement test. As shown in table IIIbelow:

Table III:The Mean Score, Standard Deviation and Calculated T-value for the Experimental and Control groups

\begin{tabular}{|l|l|l|l|l|}
\hline Group & $\begin{array}{l}\text { Mean } \\
\text { Score }\end{array}$ & SD & $d . f$ & $\begin{array}{l}\text { T-Computed } \\
\text { Values }\end{array}$ \\
\hline Exp. & 76,323 & 11,137 & 59 & 4,566 \\
\hline Con. & 62,667 & 12,214 & & \\
\hline
\end{tabular}

After applying the ETA squared equation, the effect size of the LS approach on an experimental group has achieved (0.26). Therefore, the effect size of the LS Approach is of high effect for the experimental group in the dimensional achievement test.See Figure 3 below will illustrate the high effect size of the LS approach on the experimental group when compared with the simple effect criteria, medium effect criteria, and high effect criteria: 


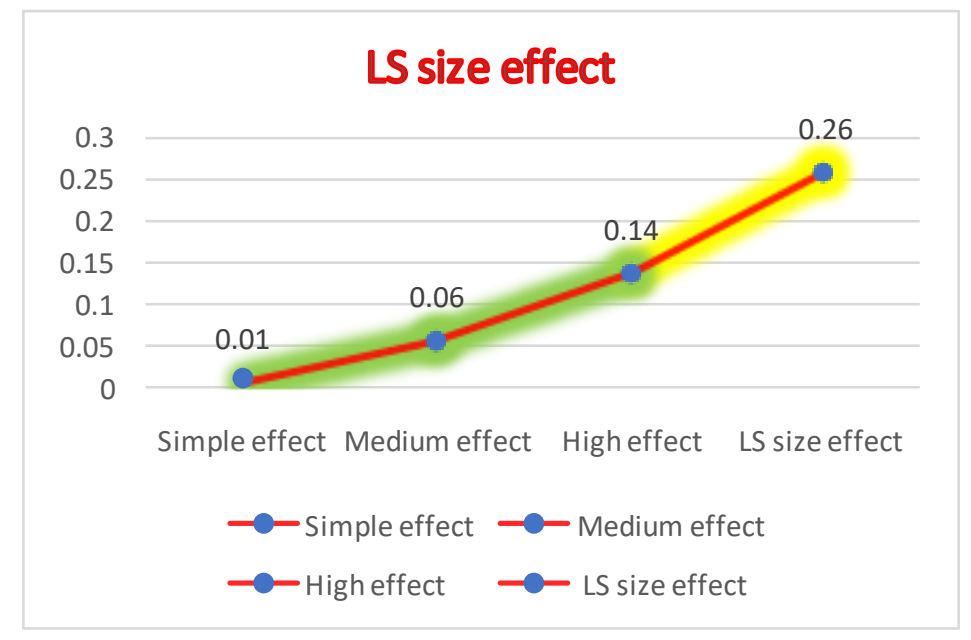

Figure 3 The Effect Size of The LS Approach in the Experimental Group

\section{CONCLUSIONS AND RECOMMENDATIONS}

In light of the findings obtained in the current experiment study, it is concluded that:

1. LS is a teaching approach that is applied on intermediate Iraqi pupils to demonstrate its positive effect on improving pupils' achievement.

2. LS Approach is discovered to have a great positive effect on engaging pupils to have full communication and also utilizing from the interaction between then and their teachers.

3. This approach (LS) helped pupils to interact more effectively by providing them with various benefits like positive participation, self-confidence, motivation, active interaction, creativity, flexibility, raising pupils' achievement scores and increasing comfortable with more understanding of material content.

4. The existence of more than one teacher has led to create more opportunities for pupils to be motivated, in which motivation has played an important role in the improvement of pupils' achievement.

5. The existence of more than one teacher has provided sufficient feedback for the pupils that led to develop the communication, discussion, exchanging ideas and improving their achievement which has a positive influence on their scores in the post-test, which were higher than their scores in the pretest and the scores of the control group.

6. The positive environment considers another factor which might help to have successful lessons. LS approach can equip an appropriate atmosphere in which pupils be more interactive and cooperative than pupils in the control group.

7. The exchanging roles among teachers, (three teachers), during the implementation of LS approach in each lesson, have helped pupils to increase their knowledge, remembering, understanding and that has led to increasing their achievement in the post-test.

8. The working of each teacher according to their exact role during the application of LS approach with taking into account the exchanging roles among them in each lesson helps to save time and effort in teaching and learning EFL in the experimental group and provides more discipline and control on the class, especially when there is a large number of pupils in the classroom.

9. It is also detected that the LS approach verifies to be efficient in displaying more scopes for the participants in the experimental group to memorize and keep what they learned through the continuing process of utilizing, repeating and joining knowledge permanently.

10. Meeting among teachers before each lesson to distribute the roles, make a discussion about the plan and the important issues to be observed, and exchange ideas and opinions give them a suitable opportunity to learn from each other, exchange advice, and enhance their ways of improving teaching.

11. The observation role of one of those teachers considered a very important role that helps teachers in LS approach to collect information about many critical issues belong to pupils such as their interaction, weakness points, attitude, and motivation during the lessons which effect on pupils' achievement, and obstacle teaching-learning process, then attempt to put solutions for the weaknesses discovered.

12. The LS approach focuses on improving the four skills in English language teaching and learning by focusing on the integration of these skills to support pupils' achievement and that attained through the 
communication, cooperation, and interaction between teachers and pupils.

The integration of the four skills, that LS approach focused, helped pupils to complete their activities, encouraged and took risks to answer even if it is wrong, then corrected these answers to avoid them later.

In the light of the current study's findings and conclusions, there are many recommendations put by the researcher, these are:

1. EFL teachers have to take into consideration their pupils' individual differences in their learning styles, personalities, interest, and their requirements, to enhance their abilities in teaching and learning in order to improve their achievement.

2. EFL teachers have to create an appropriate and positive environment inside the classroom that encouraged pupils to communicate, interact, and cooperate with each other, and also to break the anxiety, shyness, and boredom.

3.EFL teachers have to use positive and appropriate feedback by motivation and encouragement their pupils to promote them to do activities, to communicate and interact with each other by using language and take risks to answer even if the answer is wrong.

4.EFL teachers have to develop their teaching ways by reading more, searching on modern strategies and approaches, using visual ideas, and cooperating with each other to improve the teaching-learning process.

5.EFL teachers are recommended to put a suitable plan according to Educational teachers' guide to succeed in improving the pupils' achievement.

6.School leaders have to facilitate teachers meeting before and after the implementation of the LS approach.

7.To apply the LS approach, teachers have to work cooperatively with each other, make a positive discussion, and learn from each other by exchanging ideas and advice.

8.Iraqi EFL educators in ministry are invited to apply the LS approach in teaching the English language because of its benefits in saving time and effort, achieved more management, and control on pupils especially when there is a large number of pupils in the classroom.

\section{REFERENCES}

[1] Brown, J. and Rodgers, T. (2002). Doing Second Language Research. Oxford University Press.

[2] Desai P., 1986; Soviet Growth Retardation, American Economic Review, Papers and Proceedings; 67: $175-180$.

[3] Edward B. FISKE, (2000). Assessing learning achievement, printed in France, \& published by UNESCO for the INTERNATIONAL CONSULTATIVE FORUM ON EDUCATION FOR ALL.

[4] Elipane, L.E. (2012). Integrating the essential elements of Lesson Study in pre-service mathematics teacher education, IND skriftserie 27, Copenhagen: Department of Science Education.

[5] Isoda, M., 2007. A brief history in mathematics Lesson Study in Japan. In: M. Isoda, Y. Ohara, and T. Miyakawa, eds. Japanese Lesson Study in mathematics NJ: World Scientific.

[6] Lewis, C. (2002). Lesson Study: A Handbook of Teacher Led Instructional Change. Philadelphia: Research for Better Schools.

[7] Murata, A. (2011). Introduction: Conceptual Overview of Lesson Study. In L. Hart, A. Alston, \& A. Murata (Eds.) Lesson Study Research and Practice in Mathematics Education, pp. 3-12. Dordrecht: Springer.

[8] Richards, J. and Rodgers, T.S. (2014) Approaches and Methods in Language Teaching. New York: Cambridge University Press.

[9] Sarkar Arani, M. R. \& Fukaya, T. (2009) Learning beyond Boundaries: Japanese Teachers Learning to Reflect and Reflecting to Learn, Child Research Net, [Online] from, http://www.childresearch.net/RESOURCE/RESEARCH/2019/ARANI.HTM.

[10] Stigler, J., \& Hiebert, J. (1999). The teaching gap: Best ideas from the world's teachers for improving education in the classroom. New York: Free Press.

[11] Takahashi, A., \& Yoshida, M. (2004). How Can We Start Lesson Study? Ideas for establishing Lesson Study communities. Teaching Children Mathematics, 10 (9) pp. 436-443. DOI 10.1007/s10857-009-9102-7.

[12] Watanabe, T. (2002). Learning from Japanese Lesson Study. Educational Leadership, 59(6) pp. 36-39.

[13] Thompson \&Wyatt, (1952). Teaching of English in India Vol.8.pg.8 Madras, Oxford University Press.

Darling-Hammond, R. C. Wei, A. Andree, N. Richardson, and S. Orphanos, Professional Learning in the Learning Profession: A Status Report on Teacher Development in the United States and Abroad (Washington, DC: National Staff Development Council, 2009); Yoon, T. Duncan, S. W.-Y. Lee, B. Scarloss, and K. Shapley, Reviewing the evidence on how teacher professional development affects student achievement (Washington, DC: U.S. Department of Education, 2007). 